\title{
Dietary factors and breast cancer: A case control study from rural India
}

\author{
V. R. Mohite ${ }^{1}$, A. K. Pratinidhi², R. V. Mohite ${ }^{3}$ \\ ${ }^{1}$ Professor and Head, Department of Medical and Surgical Nursing, Krishna Institute of Nursing Sciences Karad, Maharashtra State, \\ India, ${ }^{2}$ Director of Research, Department of Research, Krishna Institute of Medical Sciences University Karad, Maharashtra State, India, \\ ${ }^{3}$ Assistant Professor, Department of Community Medicine, Krishna Institute of Medical Sciences Karad, Maharashtra State, India
}

\section{A B S TRA C T}

Background: Diet, a modifiable risk factor for breast cancer is estimated approximately one-third of cases could be prevented by dietary modification. Objectives: To identify possible dietary risk factors of breast cancer among newly diagnosed cases of breast cancer and to determine the strength of association of the risk factors and cancer of breast. Methods: A hospital based case- control study was conducted in Satara district, India during year 2009 to 2011 among newly diagnosed cases of breast cancer and matched controls. The total number of 217 breast cancer cases and equal number of controls age, religion and residence matched were enrolled by purposive sampling technique from selected hospitals of the study area. The data was collected individually by employing pre-tested questionnaire utilizing interview method. Descriptive statistics, Odd's ratio and chi-square test was used to find out the strength of association and statistically significant differences. Results: Maximum, $31.80 \%$ breast cancer cases were in age group 40-49 yrs with lowest age at diagnosis of disease was 25 years. Max, 63.59\%, 71.42\% and $56.68 \%$ breast cancer cases were housewives, literate and from upper economic class respectively. The risk of developing breast cancer as indicated by odd's ratio was 2.38 times higher in overweight women, 2.1 times in women consuming non-vegetarian diet, 3.9 times with women consuming extra fat in diet and 13.5 times in women with having excess salt in their diet. Conclusion: The dietary risk factors such as non-vegetarian diet, excess fat and salt in diet and overweight was strongly associated with breast cancer.

Key words: Breast cancer, Case-control, Dietary factors
Access this article online

Website:

http://nepjol.info/index.php/AJMS

\section{INTRODUCTION}

The current scenario shows that, breast cancer is the most common type of cancer in women worldwide and it has become a major public health problem under non-communicable diseases in economically developing countries. ${ }^{1}$ It is estimated that by 2030 , the global incidence of breast cancer will be increases to more than 2 million new cases per year however, in India it will reach up to 2 lacs per year. ${ }^{2}$ The most recent data available from the National Cancer Registry Programme shows a wide variation in incidence rates observed between rural and urban populations in India ranging from 36.1 in Bangalore to 7.2 in Sikkim state. ${ }^{3}$ The factors that contribute to the variation in burden of breast cancer could be due differences in life style related which include diet, addictions, availability of early detection and treatment services etc.

Epidemiological studies have shown that the incidence of breast cancer has increased in the developing countries; however there is limited data about the role of dietary factors and onset of breast cancer in these countries. The role of specific dietary factors in breast cancer causation is not completely known and some remain controversial. A substantial amount of research ${ }^{4,5}$ has explored the influence of diet, a modifiable risk factor on breast cancer risk, and it is estimated that approximately one-third of cases could be prevented by dietary modification. 
Satara, a sugar bowl district of Maharashtra state, India where $68 \%$ population resides in rural areas (census 2011) and majority of people are mainly engaged in modern agriculture and related activities for their economic development. Over the period of last two to three decades, there is socio-demographic, economic, cultural transformation among women residing in Satara district due to increase in educational level of women. This transformation has also brought about many lifestyle changes, such as an increase in the habit of smoking, use of fried, salty, spicy foods and junk foods, consumption of alcohol, obesity and some other factors which might be directly or indirectly playing important role in onset of breast cancer. Even though, the western region of Maharashtra has modern medical services, no study has study has been reported so far identify the role of dietary factors in incidence of breast cancer among the women.

The present study aimed at the estimation of the risk of developing breast cancer as a result of exposure to certain dietary factors among women residing in rural area of western Maharashtra, India. The results of this study can contribute to a better understanding of specific risk factors for breast cancer and to formulate a public health policy to increase the awareness among women and behavioral modification about the breast cancer and the related to risk factors which could be reflected in reducing the burden of the disease.

\section{MATERIAL AND METHODS}

\section{Study area}

The present study was conducted in the Satara district of the state Maharashtra, India which is spread across $10,484 \mathrm{Km}^{2}$ with a total population of 30.03 lacs. The literacy rate of the district is $84.20 \%$ of which female literacy is $76.29 \%$ (census 2011 ).

\section{Study design}

A case-control study was carried out among newly diagnosed cases of breast cancer and age, religion and residence matched controls from selected hospitals in the study area.

\section{Study setting}

The selected public and private hospitals of Satara district providing the diagnostic as well as the therapeutic cancer services were included in study to indentify and enroll the breast cancer cases.

\section{Study time}

The study was conducted over the period of thirty six months (Jan 2009 - Dec 2011).

\section{Study subjects}

All newly diagnosed cases of breast cancer i.e. within period of one year of diagnosis, irrespective of age and stage of breast cancer were eligible to be included as cases in the study.

\section{Matching}

The cases were matched with respect to number, age, religion and residence to avoid possible bias and 1:1 ratio was followed in the study.

\section{Sample size}

By purposive sampling technique, all eligible women were totaled, 434 (217 cases and 217 controls) according to inclusion and exclusion criteria of the study:

\section{Inclusion criterian}

All newly diagnosed cases of cancer breast within a period of one year of diagnosis, irrespective of stage of diagnosis of cancer breast, those with willingness to participate in study and residents of Satara district.

\section{Exclusion criteria}

Old cases of cancer breast i.e. diagnosed more than one year. Not willing to participate and not permanent residents of Satara district. Thus as per inclusion and exclusion criteria, breast cancer cases which were diagnosed in year the 2009 and 2010 totaled were 217. The same number of hospital controls were also used for the present study, thus a total of 434 women were studied.

\section{Study tools}

The data was collected by employing pre-tested questionnaire which included the information about Socio-demographiceconomic characteristics of the women and the dietary risk factors. The validity and reliability of the study tool was tested by conducting a pilot study.

\section{Ethical consideration}

Institutional ethics committee clearance, permissions from enrolled public and private hospitals and an informed consent was obtained from each study subjects before data collection.

\section{Data collection}

An individual personal interview was conducted for each study subject on scheduled time. Before the interview was started, aim of study was explained. The information was collected in vernacular language for ease of understanding and positive response from the cases and controls. The newly diagnosed cases of breast cancer and hospital based controls were interviewed at respective hospitals after discussions with the treating surgeons. The average time required to complete the questionnaire was 30 minutes. The Patient's 
comfort was maintained during the interview. Checklist was used to avoid duplication of questions and study subjects.

\section{Data analysis}

The descriptive statistics i.e. mean, standard deviation, frequency and percentages were calculated. Exposure rate of dietary risk factors and the strength of association between risk factor and disease was found out by Odd's ratio. The association between the risk factor and the breast cancer was analyzed by using chi-square test and statistical significance was considered when $\mathrm{p}$ value was less than 0.05 at $95 \%$ confidence interval.

\section{RESULTS}

A total of, 434 study subjects were interviewed in the present study which included 217 women with breast cancer and equal number of controls.

The age group ranged from minimum 25 years to maximum 70 years with the mean age of 48.6 and 48.4 yrs for the cases and the controls respectively with maximum $31.80 \%$ cases in age group 40-49 yrs. The proportions of the cases and the controls with respect to occupation shows that maximum subjects were housewives, $63.59 \%$ \& $61.75 \%$ with apparent differences in occupational groups. Both cases, $71.42 \%$ and controls, $69.58 \%$ had similar rate of literacy but showed statistically significant difference with respect to educational level $(\mathrm{p}<0.05)$. The proportion of cases had been higher in the Upper socio- economic class (56.68\%) as compared to the controls (49.30\%) (Table 1).

There were 46 women classified as overweight among cases as compared to 22 women among controls yielding an odd's ratio of 2.4(CI of 1.3-4.5) indicating overweight to be a risk factor for cancer breast. The proportion of women taking mixed diet ( Veg + Non Veg) was higher in both cases $(90.32 \%)$ and the controls $(81.56 \%)$, however the proportion of Pure Veg diet was more in the controls $(18.43 \%)$ as compared to the cases (9.68) with an odd's ratio of 2.1 (CI of 1.4 to 3.7) indicating non-veg (mixed diet) to be a risk factor for breast cancer.

The exposure rate of consumption of additional visible fat (ghee, oil, animal fat, fried food etc) in the diet was significantly higher $(68.66 \%)$ in cases as compared to the controls $(35.94 \%)(p<0.05)$ and strength of association between visible fat in the diet and breast cancer as indicated by odd's ratio of 3.9 (CI of 2.6 to 5.8) indicating dietary fat to be a risk factor for cancer breast.

The proportion of women with consumption of additional salt in the diet (in the form of extra salt or salted food items) was significantly higher $(41.93 \%)$ in cases as compare to the controls $(5.06 \%)(\mathrm{p}<0.05)$ indicating that a diet containing excess of salt to be a risk factor for breast cancer. The strength of association between excess salt in the diet and breast cancer was significant as indicated by odd's ratio of 13.5 (CI of 6.9 to 26.2).

None of the women in both cases and control groups had a history of daily consumption of fruits in diet. However proportion of women consuming fruits at least once in week was higher in cases (43.31\%) as compared to the controls $(39.63 \%)$. The proportion of women drinking of Tea/Coffee was almost similar in both cases $(98.15 \%)$ and the controls $(96.77 \%)$. An apparent difference was seen in proportions of women exposed to alcohol among cases and the controls. Consumption of fruits, drinking of tea/coffee and exposure to alcohol did not show the strength of association as indicated by odd's ratio (Table 2).

After multivariate logistic regression analysis, it was observed that nutritional factors such as an excess consumption of fat, excess salt in diet, non-veg(mixed) diet and overweight were strongly associated with occurrence of breast cancer $(\mathrm{p}<0.05)$ (Table 3$)$.

\section{DISCUSSION}

The present study from a rural area of Western Maharashtra has revealed, lowest age at incidence of breast cancer to be 25 years, with maximum $(74.19 \%)$ cases in the age group 30-60 years. Similar findings also have been noted by Pakseresht $\mathrm{S}$ et al from Delhi ${ }^{6}$ and Kamat R from Udapi, Karnataka ${ }^{7}$ as higher number of breast cancer cases in age group of 30-60 yrs with lowest age at incidence of breast cancer to be less than 30 years.

The study shows, majority of breast cancer cases $(63.89 \%)$ are housewives and literate $(71.43 \%)$. A similar finding is also observed by Pakseresht $\mathrm{S}$ et al from Delhi, ${ }^{6}$ however, Parameshwari $\mathrm{P}^{8}$ from South Kerala have shown that higher proportion $(60 \%)$ of cases to be illiterate and housewives. Even though in Kerala women have high literacy rate i.e. $>90 \%$, majority of breast cancer cases have been illiterate and difference in study results could be due to behaviour of majority of literate women from Kerala preferring residence abroad or in metros and illiterate ones reside in local area.

In the present study, the rate of occurrence of breast cancer cases is higher among women from upper economic class. A study is conducted in rural area but modern agriculture, cash crop of sugar cane associated with higher economic 


\begin{tabular}{|c|c|c|c|c|c|}
\hline \multirow[t]{2}{*}{ Variables } & \multicolumn{2}{|c|}{ Group } & \multirow[t]{2}{*}{ Total no (\%) } & \multirow[t]{2}{*}{ Test of significance } & \multirow[t]{2}{*}{$P$ value } \\
\hline & Case no (\%) & Control no (\%) & & & \\
\hline \multicolumn{6}{|l|}{ Age (yrs) } \\
\hline$\leq 30$ & $7(3.23)$ & $7(3.23)$ & $14(3.22)$ & 0.14 & 0.88 \\
\hline $30-39$ & $40(18.43)$ & $40(18.43)$ & $80(18.43)$ & & \\
\hline $40-49$ & $69(31.80)$ & $69(31.80)$ & 138 (31.79) & & \\
\hline $50-59$ & $52(23.96)$ & $53(24.42)$ & 105 (24.19) & & \\
\hline$\geq 60$ & 49 (22.58) & $48(22.12)$ & 97 (22.35) & & \\
\hline \multicolumn{6}{|l|}{ Occupation } \\
\hline House wife & 138 (63.59) & $134(61.75)$ & $272(62.67)$ & 7.75 & 0.100 \\
\hline Daily wages & $36(16.59)$ & $48(22.12)$ & 84 (19.35) & & \\
\hline Self employed & $35(16.13)$ & $23(10.60)$ & $58(13.36)$ & & \\
\hline Civil servant & $5(2.30)$ & $3(1.38)$ & $8(1.84)$ & & \\
\hline Private sector & $3(1.38)$ & $9(4.15)$ & $12(2.76)$ & & \\
\hline \multicolumn{6}{|l|}{ Education } \\
\hline Illiterate & $62(28.57)$ & $66(30.41)$ & $128(29.49)$ & 16.33 & $0.002^{*}$ \\
\hline Primary & $68(31.34)$ & 39 (17.97) & $107(24.65)$ & & \\
\hline Secondary & $73(33.64)$ & 95 (43.78) & $168(38.70)$ & & \\
\hline Higher secondary & $6(2.76)$ & $14(6.45)$ & $20(4.60)$ & & \\
\hline Degree/deploma & $8(3.69)$ & $3(1.38)$ & $11(2.53)$ & & \\
\hline \multicolumn{6}{|l|}{ Income } \\
\hline Lowe class & $94(43.32)$ & $110(50.69)$ & $218(50.23)$ & 2.3 & 0.12 \\
\hline Upper class & $123(56.68)$ & $107(49.31)$ & $216(49.76)$ & & \\
\hline
\end{tabular}

\begin{tabular}{|c|c|c|c|c|c|c|c|}
\hline \multirow[t]{2}{*}{ Dietary status } & \multicolumn{2}{|c|}{ Group } & \multirow[t]{2}{*}{ Total no (\%) } & \multirow[t]{2}{*}{ Odd's } & \multirow[t]{2}{*}{$\mathrm{Cl}$} & \multirow{2}{*}{$\begin{array}{c}\chi^{2} \\
\text { Statistic }\end{array}$} & \multirow[t]{2}{*}{$P$ value } \\
\hline & Case no (\%) & Control no (\%) & & & & & \\
\hline \multicolumn{8}{|l|}{ BMI } \\
\hline$<18.5$ & $25(11.52)$ & $45(20.74)$ & $70(16.12)$ & 2.38 & $1.3-4.5$ & 14.23 & $0.008^{*}$ \\
\hline 18.5 to 24.9 & $146(67.28)$ & $150(69.12)$ & $296(68.20)$ & & & & \\
\hline$>25$ & $46(21.20)$ & $22(10.14)$ & $68(15.66)$ & & & & \\
\hline \multicolumn{8}{|l|}{ Diet } \\
\hline Pure veg & $21(9.68)$ & $40(18.43)$ & $61(14.05)$ & 2.1 & $1.4-3.7$ & 20.05 & $0.001^{*}$ \\
\hline Mixed diet & $196(90.32)$ & $177(81.56)$ & 373 (85.94) & & & & \\
\hline \multicolumn{8}{|l|}{ Fat in diet } \\
\hline Additional fat in diet & $149(68.66)$ & $78(35.94)$ & $227(52.30)$ & 3.9 & $2.6-5.8$ & 70.06 & $0.001^{*}$ \\
\hline Regular fat in diet & $68(31.34)$ & $139(64.06)$ & 207 (47.69) & & & & \\
\hline \multicolumn{8}{|l|}{ Salt in diet } \\
\hline Diet with regular salt & $126(58.0)$ & $206(94.93)$ & 332 (76.49) & 13.5 & $6.9-26.2$ & 79.9 & $0.001^{*}$ \\
\hline Diet with extra salt & $91(41.93)$ & $11(5.06)$ & $102(23.50)$ & & & & \\
\hline \multicolumn{8}{|l|}{ Fruits in diet } \\
\hline Yes & $94(43.31)$ & $86(39.63)$ & 180 (41.47) & 1.1 & $0.7-1.7$ & 0.60 & 0.436 \\
\hline No & $123(56.68)$ & $131(30.18)$ & 254 (58.52) & & & & \\
\hline \multicolumn{8}{|l|}{ Tea/coffee drinking } \\
\hline Yes & $213(98.15)$ & $210(96.77)$ & $423(97.46)$ & 1.7 & $0.5-6.1$ & 0.373 & 0.541 \\
\hline No & $4(1.84)$ & $7(3.22)$ & $11(2.53)$ & & & & \\
\hline \multicolumn{8}{|l|}{ Alcohol } \\
\hline Yes & $6(2.76)$ & $9(4.14)$ & $15(3.45)$ & 0.65 & $0.2-1.8$ & 0.27 & 0.59 \\
\hline No & $201(97.24)$ & $197(95.86)$ & 398 (96.55) & & & & \\
\hline
\end{tabular}

\begin{tabular}{|c|c|c|c|c|c|c|}
\hline Study variables & B & S.E. & Wald & Df & Sig. & $\operatorname{Exp}(B)$ \\
\hline Overweight & -2.835 & 0.649 & 23.017 & 1 & 0.000 & 0.072 \\
\hline Use of animal fat & -2.135 & 0.680 & 9.872 & 1 & 0.002 & 0.118 \\
\hline Extra salt & -2.714 & 0.438 & 38.353 & 1 & 0.000 & 0.066 \\
\hline Non-veg (mixed diet) & -2.619 & 0.639 & 21.63 & 1 & 0.000 & 0.061 \\
\hline
\end{tabular}

status, increased literacy, sound economic status could be responsible for high incidence of breast cancer among upper economic class rural population. Similar findings have been observed by Kelsey $\mathrm{JL}^{9}$ from developed countries indicating the transition of disease from developed to developing country. 
In the present study, risk of developing breast cancer in overweight women is 2.5 times higher than normal weight women with significant statistical association $(p<0.05)$. The study conducted by Pakseresht $\mathrm{S}$ et al from Delhi, ${ }^{6}$ Rama Lodha from Bhopal ${ }^{10}$ and by Vahit Ozmen from Turk ${ }^{11}$ have reported 1.06, 2.27 and 2.10 times the risk of developing breast cancer in overweight women as compared to normal weight women. It is estimated that women with a $\mathrm{BMI}$ of $\geq 25$ have a $58 \%$ increased risk of developing breast cancer. ${ }^{12}$ The overweight women have reduced progesterone levels because obesity may cause anovulation and a decreased production of progesterone in the luteal phase. Obesity also increases levels of endogenous estrogen and decreases sex hormone binding globulin which increases levels of free estradiol. ${ }^{13,14}$

The risk of development of breast cancer is 4 times higher in women consuming excess of visible fat (ghee, oil, animal fat etc) in the diet as compared to the controls. Similar observations have also been made by Spiegleman CE, ${ }^{15}$ Kamarudin $\mathrm{R}$ et al, ${ }^{16}$ Han DF et $\mathrm{al}^{17}$ and Aida Adil Abdul from Bahrain. ${ }^{18}$ European Prospective Investigation into Nutrition and Cancer (EPIC) Study has reported that eating a high fat diet significantly increases the risk of breast cancer; women who have had a $35 \%$ and $39 \%$ fat content in the diet are at a greater risk. ${ }^{19}$ It is also observed that the dietary fat may increase breast cancer by inducing endogenous estrogen levels. ${ }^{20}$ The proportion of women taking mixed diet i.e. vegetarian as well as non- vegetarian shown a higher risk of developing breast cancer as compared to women taking pure vegetarian diet with an odd's ratio of 2.1 (CI of 1.4 to 3.7). It is very rare in Indian culture that any human either a man or a woman consuming a non-vegetarian diet on daily basis, so considering this, mixed diet is considered as non-vegetarian in present study. In a cohort study conducted by Taylor EF et al on over 35,000 women from UK observed have that, meat consumption to be significantly increasing the risk of breast cancer. ${ }^{21}$ Similarly, a study in Kerala of 264 women with breast cancer has shown an increased risk of breast cancer associated with a non-vegetarian diet (OR 1.82 (95\% CI 1.11-2.98)). ${ }^{22}$

It is observed that consumption of fruits gives protective effect against breast cancer due to their antioxidant and fiber contents. Our study depicts that there is no role of development of breast cancer and consumption of fruits. Similar observations have also been made by Van Gils et al from Netherlands, ${ }^{23}$ Aida Adil Abdul from Bahrain ${ }^{18}$ and Han DF from China. ${ }^{17}$ The failure to show a significant difference could be due to low exposure to fruits in study groups. The present study depicts the risk of developing breast cancer is 13.5 times higher among the women who consume extra salt in their diet with a significant statistical difference $(p<0.05)$. This is been reported for the first time and such findings till date has not been observed by anybody from anywhere. Salt consumption is also suspected to contribute to insulin resistance and metabolic syndrome, which themselves may be associated with increased risk of breast cancer.

The worldwide data have shown that the relative risk of breast cancer is increased [OR of 1.32 (95\% CI 1.19-1.45)] in women who have reported drinking alcohol compared to women who have reported no alcohol intake. ${ }^{24,25,26}$ However, present study could not show any significant relationship between alcohol and breast cancer as women rarely resort to consumption of alcohol due to Indian culture, social stigma and family and community influences.

\section{CONCLUSION}

The dietary risk factors such as excess consumption of visible fat, extra salt in diet, non-vegetarian diet and overweight are significantly associated with occurrence of breast cancer among Indian women. However, worldwide alcohol is a known risk factor of breast cancer but study could not reveal any risk associated with it.

\section{ACKNOWLEDGEMENT}

We thank to Dr Suresh Bhosale, Chairman and managing trustee, Krishna Charitable Trust Karad, Maharashtra State, India for continuous support and motivation for research. We also thank Dr AY Kshirsagar, Medical Director, Krishna Hospital and Medical Research Centre Karad, Maharashtra State, India to support this study.

We are also gratefully thanking to all study participants for support this study.

\section{REFERENCES}

1. Parkin DM, Whelan SL, Ferlay J, Temppo $L$ and Thomas DB. Cancer Incidence in Five Continents. WHO - IARC Scientific publication 2003; 155.

2. Ferlay J, Shin HR, Bray F, Forman D, Mathers C, and Parkin DM. Estimates of worldwide burden of cancer in 2008. Int J Cancer 2010; Vol 12:2893-2917.

3. Indian Council of Medical Research. Development of cancer atlas of India- A project of National Cancer Registry Program. First All India Report 2002; 11-18.

4. Rohan TE, McMichael AJ and Baghurst PAA. Population-based case-control study of diet and breast cancer in Australia. Am J Epidemiol 1988;128:478-489.

5. Howe GR, Hirohata T and Hislop TG. Dietary factors and risk of breast cancer: combined analysis of 12 case-control studies. J Natl Cancer Inst 1990; 82:561-569.

6. Pakseresht S, Ingale GK, Bahadur AK, Ramteke VK, Singh MM, Garg S et al. Risk factors with breast cancer among women in Delhi. Indian J Cancer 2009; 46:132-138. 
7. Kamat R, Mahajan KS and Ashok L. A study on risk factors of breast cancer among patient attending the tertiary care hospital, in Udupi district. Indian J Community Medicine,2013;38:95-99.

8. Parameshwari $\mathrm{P}$ and Mathukumar K. A population based case control study on breast cancer and the associated risk factors in a rural setting in Kerala. J Clin Diagn Res. 2013; Vol 7(9):1913-1916.

9. Kelsey JA. Review of epidemiology of human breast cancer. Epidemiol Review 1979;1:74-109.

10. Lodha Rama, Nandeshwar S, Pal DK, Shrivastav A, Lodha KM, Bhagat VK, et al. Risk factors for breast cancer among women in Bhopal urban Agglomerate: a case control study. Asian Pacific J Cancer Prev 2011; 2111-2115.

11. Ozmen V, Ozcinar B, Karanlik H, Cabioglu N, Tukenmez M, Disci R, et al. Breast cancer risk factors in Turkish women- a university hospital based nested case control study. World Journal of Surgical Oncology 2009;7:37.

12. Hirose $\mathrm{K}$, Matsuo $\mathrm{K}$, Iwata $\mathrm{H}$ and Tajima K. Dietary patterns and the risk of breast cancer in Japanese women. Cancer Sci 2007; 98(9):1431-1438.

13. Key TJ, Verkasalo PK and Banks E. Epidemiology of breast cancer. Lancet Oncol. 2001; 2:133-140.

14. McTiernan A. Obesity and cancer: the risks, science, and potential management strategies. Oncology 2005; 19(7):871-881.

15. Spiegleman CE and Hunter DJ. Premenopausal fat intake and the risk of breast cancer. J Nati Cancer Inst, 2003;95:1079-1085.

16. Kamarudin R, Shah SA and Hidayah N. Lifestyle factors and breast cancer. A case control study in Kuala Lumpur, Malaysia. Asian Pacific J Cancer Prev 2006;7(1): 51-54.

17. Han DF and Ma J. A case control study on the risk of female breast cancer in Wuhan area. Zhonghua Liu Xing Bing Xue Za ZHI, 2004; Vol 25(3):256-260.
18. Aida Adil Abdul-Samad. Breast cancer and selected lifestyle variables: a case-control study. Bahrain Medical Bulletin, 2009; 31(4).

19. Schulz M, Hoffmann K, Weikert C, Nöthlings U, Schulze MB and Boeing $\mathrm{H}$. Identification of a dietary pattern characterized by high-fat food choices associated with increased risk of breast cancer: the European Prospective Investigation into Cancer and Nutrition (EPIC)-Potsdam Study. Br J Nutr 2008; 1:1-5.

20. Dorgan JF, Hunsberger SA, McMahon RP, Kwiterovich PO, Lauer RM, Van Horn L, et al. Diet and sex hormones in girls: findings from a randomized controlled clinical trial. J Natl Cancer Inst 2003; 95(2):132-141.

21. Taylor EF, Burley VJ, Greenwood DC and Cade JE. Meat consumption and risk of breast cancer in the UK Women's Cohort Study. Br J Cancer 2007; 96(7):1139-1146.

22. Jayalekshmi P, Varughese $S$, Kalavathi, Nair M, Jayaprakash $V$ and Gangadharan P. A Nested Case-Control Study of Female Breast Cancer in Karunagappally Cohort in Kerala, India Asian Pacific J Cancer Prev 2009; 10: 241-246.

23. Van Gils. Consumption of vegetables and fruits and risk of breast cancer. JAMA 2005; 12(2):183-193.

24. Horn-Ross PL, Canchola AJ, West DW, Stewart SL, Bernstein L, Deapen D, et al. Patterns of alcohol consumption and breast cancer risk in the California Teachers Study cohort. Cancer Epidemiol Biomarkers Prev 2004; 13(3):405-411.

25. Tjonneland A, Christensen J, Thomsen BL, Olsen A, Stripp C, Overvad K, et al. Lifetime alcohol consumption and postmenopausal breast cancer rate in Denmark: a prospective cohort study. J Nutr 2004;134(1):173-178.

26. Berstad $\mathrm{P}, \mathrm{Ma} \mathrm{H}$, Bernstein $\mathrm{L}$ and Ursin $\mathrm{G}$. Alcohol intake and breast cancer risk among young women. Breast Cancer Res Treat 2008;108(1):113-120.

\footnotetext{
Authors Contribution:

VRM - Contributed for study design, literature search and data collection; AKP - Designed the study and reviewed the manuscript; RVM - Analysis of data and drafted the manuscript.
}

Source of Support: Nil, Conflict of Interest: None declared 